\title{
The Impact of the SARS-CoV-2 Epidemic on World Indices: The Entropy Approach
}

\author{
Ayşe Metin Karakaş (D), ${ }^{1}$ Mine Doğan $\mathbb{D}^{2},{ }^{2}$ and Sinan Çalik $\mathbb{D}^{2}$ \\ ${ }^{1}$ Department of Statistics, Faculty of Art and Science, Bitlis Eren University, Bitlis, Turkey \\ ${ }^{2}$ Department of Statistics, Faculty of Science, Firat University, Elaziğ, Turkey \\ Correspondence should be addressed to Ayşe Metin Karakaş; aysekarakas5767@gmail.com
}

Received 10 December 2020; Revised 16 January 2021; Accepted 11 February 2021; Published 26 February 2021

Academic Editor: Mustafa Inc

Copyright (c) 2021 Ayşe Metin Karakaş et al. This is an open access article distributed under the Creative Commons Attribution License, which permits unrestricted use, distribution, and reproduction in any medium, provided the original work is properly cited.

\begin{abstract}
The coronavirus disease (COVID-19) outbreak started in December 2019 in Wuhan. The virus has spread around the whole world, and it has caused a strong and serious pandemic. Symptoms such as cough, respiratory distress, diarrhea, and fatigue associated with COVID-19 are typical clinical findings. Coronavirus infection has become an important public health concern because of its increasing prevalence, serious complications, and mortality. In light of this information, we examine different entropy methods for world indices (ISE 30, FTSE 100, NIKKEI 225, SP 500, and DAX 30) in the pre-COVID-19 period (02.01.2019-17.11.2019) and the post-COVID-19 period (18.11.2019-23.11.2020) in this article. Besides, we discuss the performances of entropies such as Shannon, Renyi, Tsallis, and approximate entropy (ApEn) in detail and perform the notion of entropy for volatility measure. As a result, we present the numerical results for the data set.
\end{abstract}

\section{Introduction}

Entropy is a word that goes back to 1865 when Rudolf Clausius, a German physicist, granted an original noun to irreparable warmth damage termed as equivalent value. The word entropy was chosen for the fact that entropies refer to average component transformative or transformation component in Greek [1]. Tsallis [2] suggests that the concept of entropy should be widened into a notion bearing the statistical status of complicated systems. Then, Rao et al. [3] put forward the cumulative residual entropy, generalized measure of ambiguity, and applied it in reliability and picture arrangement as well as nonadditive measures of entropy. In 2008, Pincus [4] pointed out the use of approximate entropy (ApEn), a model-independent measure of consecutive disorder. Thus, through utilizing a number of varied practices for both empirical data and model-based data, he conceived cross-ApEn, concerning two-variable asynchrony measure that provides a stronger and more omnipresent measure of bivariate correspondence than correlation. In addition, he presented the following containments to various strategies, ensured analytic statements for statistical properties of ApEn, and cross-checked ApEn with nonlinear measures, correlation, and spectral analyses as well as other entropy measures. Later, Ubriaco [5] applied the derivative to a special probability function and obtained the Shannon entropy definition which is based on probability and derivative. The information and its management can be illustrated by entropy. Most information management techniques are based on entropy. The fractional-order derivative and entropy-based binomial distribution yield a series of symmetric functions. Rompolis [6] put forward a varied method to apply the maximum entropy basis for recovering the risk neutral density of forthcoming stock, or any other entity which returns from put prices. In 2015, Sati and Gupta [7] defined a generalized cumulative remaining entropy on the basis of the nonadditive Tsallis entropy. In the same year, Sheraz et al. [8] employed an entropy for volatility markets. Then, Stosic et al. [9] investigated the effect of financial attacks on foreign exchange (FX) markets using the time-dependent block entropy technique and revealed experimental conclusions 
which explain that the financial attacks are corporate with an important rise in exchange rate entropy, echoing uncertainty in FX market dynamics. The study in [10] shows every minute of the six years of entropy-dependent usage data between 1999 and 2004 based on time series and volatility, and that the entropy of the fluctuation series is based on the stock market. Khammar and Jahanshahi [11] submitted the weighted condition of this measure and named it "Weighted Cumulative Residual Tsallis Entropy (WCRTE)" and showed that it can specify the value of the survival function and Rayleigh distribution in a unique way. In 2019, Karakas [12] has attained volatility of ethereum and bitcoin, and then, the same author [13] used the world indices such as Istanbul Stock Indices (BIST 30), Brazil Index (Bovespa), Germany Index (DAX 30), Britain Index (FTSE100), South Korea (KOSPI), Japan Index (NIKKEI 225), United States Index (S\&P 500), and China Index (SHANGAI) that have been examined over 8 years between 2010 and 2018, and, as a result, found the entropy notion for volatility measure to draw a comparison. Inc et al. [14] obtained approximate solutions of the nonlinear time-dependent generalized Fitzhugh-Nagumo equation with time-dependent coefficients and Sharma-Tasso-Olver equation subjected to certain initial conditions and showed that this method is efficient and convenient and, thus, it can be applied to a variety of problems. The approximate solutions are compared with the exact solutions. Then, Acay and Inc [15] proposed the temperature dynamics of a building and examined this model which has a crucial place in daily life. In 2020, Houwe et al. [16] investigated analytical solutions for the nonlinear differential-difference equations (DDEs) having fractional-order derivatives and employed the discrete tanh method in computations. As well, Akinlar et al. [17] considered an epidemic disease system by an additive fractional white noise to show that epidemic diseases may be more competently modeled in the fractional-stochastic settings than the ones modeled by deterministic differential equations, generated a new SIRS model and perturbed it to the fractional-stochastic systems, and studied chaotic behavior at disease-free and endemic steady-state points on these systems. After that, Akinlar et al. [18] considered a novel contribution because optimal control formulations, numerical solutions, and stability analysis for the fractionalorder Malkus model are studied for the first time in this paper. Later, in the same year, Korpinar et al. [19] analyzed the fractional-stochastic quadratic-cubic nonlinear Schrödinger equation (QC-NLSE) describing the propagation of solitons through optical fibers and employed it to obtain stochastic solutions in the white noise space with Hermite transformation. Besides, Hashemi et al. [20] used the Adams-Bashforth-Moulton scheme (ABMS) to determine the approximate solution of a variable-order fractional three-dimensional chaotic process, demonstrating simulation results. However, Qureshi [21] examined a new timeinvariant nonlinear mathematical model in fractional(noninteger-) order settings that has been proposed under the three most frequently employed strategies of the classical Caputo. Currently, all world stock markets have been affected by the virus. The COVID-19 virus first emerged in
China (Wuhan city) spreading around the world. This virus is amongst the deadliest virus known to humans all over, having deadly effect on the health care system of most of the countries. In this study, five world indices (ISE 30, FTSE 100, SP 500, NIKKEI 225, and DAX 30) were used to investigate based on the entropy approach in the pre-COVID-19 period (02.01.2019-17.11.2019) and post-COVID-19 period (18.11.2019-23.11.2020).

\section{Materials and Methods}

2.1. Shannon Entropy and Renyi Entropy. Shannon entropy states that a measure of the amount of information ${ }_{S}(p)$ containing a series of events of $p_{1}, p_{2}, \ldots, p_{N}$ should satisfy three requirements:

\section{$S$ should be continuous in $p_{i}$}

If all $p_{i}$ are equal probably, then $S$ should be a monotonic increasing function of $\mathrm{N}$

\section{$\mathrm{S}$ should be additive}

Then, it proves that only $S$ satisfying these three requirements shows

$$
S(P)=-\kappa \sum_{i=1}^{N} p_{i} \ln p_{i}
$$

where $\kappa$ is a positive constant. This quantity has since become known as the Shannon entropy. In the information theory applications, the asymptotic equipartition property of Shannon is given for $T \subseteq S^{n} T \subseteq S^{n}$ with

$$
|T| \leq e^{n(S(\rho)+\varepsilon)},
$$

such that illustration $n$ times from $P$ yields a factor of $T$ with probability $>1-\varepsilon$ and $\varepsilon \longrightarrow 0$ as $n \longrightarrow \infty$. Extensions of Shannon's original work have resulted in many alternative measures of information or entropy. For instance, by relaxing the third point of Shannon's requirements, that of additivity, Renyi was able to extend Shannon entropy to a continuous family of entropy measures:

$$
S_{q}(P)=-\frac{1}{1-q} \ln \sum_{i=1}^{N} p_{i}^{q}
$$

The Renyi entropy tends to Shannon entropy as $q \longrightarrow 1$. The Renyi entropy is as follows:

The scaling factor is conventional, i.e., it makes $S_{q}$ nonnegative for all $q$ and ensures $S_{q}\left(u_{n}\right)=\log n$, where $u_{n}$ is the uniform distribution on an $n$-element set.

The main property which the Renyi entropy has in common with Shannon entropy is additivity:

$$
S_{q}(\rho \times r)=S_{q}(\rho)+S_{q}(r) .
$$

For $\beta=0$, acquire the min-entropy, which is the cardinality of the support of $\rho: S_{0}(\rho)=\log |\{i \in S \mid \rho(i)>0\}|$. For $q=1$, acquire Shannon entropy: 
TABLE 1: Statistics of world indices in the pre-COVID-19 period (02.01.2019-17.11.2019).

\begin{tabular}{|c|c|c|c|c|c|}
\hline & ISE 30 & FTSE 100 & NIKKEI 225 & SP 500 & DAX 30 \\
\hline Mean & 1226,0519 & 7262,6528 & 21358,17 & 2896,640 & 11998,00 \\
\hline Median & 1237,215 & 7274,450 & 21360,09 & 2909,190 & 12034,17 \\
\hline Maximum & 1327,420 & 7686,610 & 23520,01 & 3121,750 & 13289,46 \\
\hline Minimum & 1045,03 & 6692,660 & 19561,96 & 2605,500 & 10416,66 \\
\hline Std. dev. & 65,32040 & 186,4341 & 873,4083 & 113,5172 & 604,7448 \\
\hline Skewness & -0.674607 & -0.599872 & 0.217312 & -0.379169 & -0.031424 \\
\hline Kurtosis & 2.731324 & 3.472528 & 3,208747 & 2.768171 & 2.689980 \\
\hline Jarque-Bera & 17.50623 & 15.79535 & 2.208500 & 5.973792 & 0.950594 \\
\hline Probability & 0.000158 & 0.000372 & 0.033145 & 0.005044 & 0.006217 \\
\hline
\end{tabular}

TABLE 2: Statistics of world indices in the post-COVID-19 period (18.11.2019-23.11.2020).

\begin{tabular}{|c|c|c|c|c|c|}
\hline & ISE 30 & FTSE 100 & NIKKEI 225 & SP 500 & DAX 30 \\
\hline Mean & 1287,1338 & 6379,9955 & 22412,79 & 3165,256 & 12329,73 \\
\hline Median & 1297,285 & 6123,820 & 23112,88 & 3232,250 & 12822,26 \\
\hline Maximum & 1496,790 & 7674,560 & 26014,62 & 3623,000 & 13789,00 \\
\hline Minimum & 1014,100 & 4993,890 & 16552,83 & 2220,500 & 8441,710 \\
\hline Std. dev. & 106,5718 & 699,3948 & 1827,824 & 279,4826 & 1209,913 \\
\hline Skewness & -0.250346 & 0.617331 & -1.175042 & -0.974508 & -1.297747 \\
\hline Kurtosis & 2.706596 & 2.110804 & 3,951717 & 3,539609 & 3.795668 \\
\hline Jarque-Bera & 3.592315 & 24.79044 & 68.84024 & 43.79541 & 78.91692 \\
\hline Probability & 0.016593 & 0.000004 & 0.000000 & 0.000000 & 0.000000 \\
\hline
\end{tabular}

TABle 3: Different entropy measures of ISE 30, FTSE 100, NIKKEI 225, SP 500, and DAX 30 in the pre-COVID-19 period (02.01.2019-17.11.2019).

\begin{tabular}{|c|c|c|c|c|c|c|}
\hline \multicolumn{3}{|c|}{ Shannon } & \multicolumn{2}{|c|}{ Tsallis } & \multirow{2}{*}{$\begin{array}{l}\text { Renyi } \\
\text { Value }\end{array}$} & \multirow{2}{*}{$\begin{array}{c}\text { Approximate entropy } \\
\text { Value }\end{array}$} \\
\hline Method & Value & $\mathrm{q}$ & Value & $\mathrm{r}$ & & \\
\hline \multicolumn{7}{|l|}{ ISE 30} \\
\hline ML & 5.396743 & 0 & 220.0000000 & 0 & 5.398163 & \multirow{11}{*}{0.7846485} \\
\hline MM & 5.397149 & 0.2 & 92.5761790 & 0.25 & 5.397804 & \\
\hline Jefferys & 5.396744 & 0.4 & 40.8280410 & 0.5 & 5.397448 & \\
\hline Laplace & 5.396745 & 0.6 & 19.1544962 & 1 & 5.396743 & \\
\hline SG & 5.396743 & 0.8 & 9.7146361 & 2 & 5.395365 & \\
\hline Minimax & 5.396749 & 1 & 5.3967431 & 4 & 5.392732 & \\
\hline $\mathrm{CS}$ & 5.396743 & 1.2 & 3.3008212 & 8 & 5.387939 & \\
\hline \multirow[t]{4}{*}{ Shrink } & \multirow[t]{4}{*}{5.39745} & 1.4 & 2.2112471 & 16 & 5.380020 & \\
\hline & & 1.6 & 1.6012332 & 32 & 5.368983 & \\
\hline & & 1.8 & 1.2333170 & 64 & 5.356709 & \\
\hline & & 2 & 0.9954624 & Infinite & 5.319076 & \\
\hline \multicolumn{7}{|c|}{ FTSE 100} \\
\hline $\mathrm{ML}$ & 5.424631 & 0 & 226.0000000 & 0 & 5.424950 & \multirow{11}{*}{0.7947985} \\
\hline $\mathrm{MM}$ & 5.424699 & 0.2 & 94.6256717 & 0.25 & 5.424870 & \\
\hline Jefferys & 5.424631 & 0.4 & 41.5280750 & 0.5 & 5.424790 & \\
\hline Laplace & 5.424631 & 0.6 & 19.3935912 & 1 & 5.424631 & \\
\hline SG & 5.424631 & 0.8 & 9.7962946 & 2 & 5.424315 & \\
\hline Minimax & 5.424631 & 1 & 5.4246308 & 4 & 5.423694 & \\
\hline $\mathrm{CS}$ & 5.424631 & 1.2 & 3.3103449 & 8 & 5.422489 & \\
\hline \multirow{4}{*}{ Shrink } & \multirow{4}{*}{5.424754} & 1.4 & 2.2144993 & 16 & 5.420221 & \\
\hline & & 1.6 & 1.6023437 & 32 & 5.416139 & \\
\hline & & 1.8 & 1.2336962 & 64 & 5.409257 & \\
\hline & & 2 & 0.9955919 & Infinite & 5.368548 & \\
\hline \multicolumn{7}{|c|}{ NIKKEI 225} \\
\hline ML & 5.424339 & 0 & 226.0000000 & 0 & 5.424950 & \multirow{3}{*}{0.689666} \\
\hline MM & 5.424363 & 0.2 & 94.6212737 & 0.25 & 5.424798 & \\
\hline Jefferys & 5.424339 & 0.4 & 41.5250909 & 0.5 & 5.424646 & \\
\hline
\end{tabular}


TABle 3: Continued.

\begin{tabular}{|c|c|c|c|c|c|c|}
\hline \multicolumn{3}{|c|}{ Shannon } & \multicolumn{2}{|c|}{ Tsallis } & \multirow{2}{*}{$\begin{array}{l}\text { Renyi } \\
\text { Value }\end{array}$} & \multirow{2}{*}{$\begin{array}{c}\text { Approximate entropy } \\
\text { Value }\end{array}$} \\
\hline Method & Value & $\mathrm{q}$ & Value & $\mathrm{r}$ & & \\
\hline Laplace & 5.424339 & 0.6 & 19.3920726 & 1 & 5.424339 & \\
\hline SG & 5.424339 & 0.8 & 9.7956076 & 2 & 5.423721 & \\
\hline Minimax & 5.42434 & 1 & 5.4243394 & 4 & 5.422458 & \\
\hline CS & 5.424339 & 1.2 & 3.3102262 & 8 & 5.419834 & \\
\hline \multirow[t]{4}{*}{ Shrink } & 5.424384 & 1.4 & 2.2144524 & 16 & 5.414208 & \\
\hline & & 1.6 & 1.6023255 & 32 & 5.402104 & \\
\hline & & 1.8 & 1.2336893 & 64 & 5.381751 & \\
\hline & & 2 & 0.9955893 & Infinite & 5.333581 & \\
\hline \multicolumn{7}{|l|}{ SP 500} \\
\hline ML & 5.424201 & 0 & 226.0000000 & 0 & 5.424950 & \\
\hline MM & 5.424373 & 0.2 & 94.6190516 & 0.25 & 5.424762 & 0.6455126 \\
\hline Jefferys & 5.424202 & 0.4 & 41.5236068 & 0.5 & 5.424575 & \\
\hline Laplace & 5.424202 & 0.6 & 19.3913293 & 1 & 5.424201 & \\
\hline SG & 5.424201 & 0.8 & 9.7952767 & 2 & 5.423462 & \\
\hline Minimax & 5.424203 & 1 & 5.4242014 & 4 & 5.422009 & \\
\hline CS & 5.424201 & 1.2 & 3.3101709 & 8 & 5.419211 & \\
\hline \multirow[t]{4}{*}{ Shrink } & 5.424507 & 1.4 & 2.2144308 & 16 & 5.414035 & \\
\hline & & 1.6 & 1.6023173 & 32 & 5.405173 & \\
\hline & & 1.8 & 1.2336862 & 64 & 5.391980 & \\
\hline & & 2 & 0.9955882 & Infinite & 5.350668 & \\
\hline \multicolumn{7}{|l|}{ DAX 30} \\
\hline ML & 5.42371 & 0 & 226.0000000 & 0 & 5.424950 & \\
\hline MM & 5.423752 & 0.2 & 94.6115378 & 0.25 & 5.424640 & 0.5535031 \\
\hline Jefferys & 5.42371 & 0.4 & 41.5185260 & 0.5 & 5.424329 & \\
\hline Laplace & 5.42371 & 0.6 & 19.3887524 & 1 & 5.423710 & \\
\hline SG & 5.42371 & 0.8 & 9.7941149 & 2 & 5.422476 & \\
\hline Minimax & 5.423712 & 1 & 5.4237103 & 4 & 5.420029 & \\
\hline CS & 5.42371 & 1.2 & 3.3099716 & 8 & 5.415223 & \\
\hline \multirow[t]{4}{*}{ Shrink } & 5.423792 & 1.4 & 2.2143522 & 16 & 5.406039 & \\
\hline & & 1.6 & 1.6022869 & 32 & 5.389845 & \\
\hline & & 1.8 & 1.2336746 & 64 & 5.367814 & \\
\hline & & 2 & 0.9955838 & Infinite & 5.323234 & \\
\hline
\end{tabular}

TABle 4: Different entropy measures of ISE 30, FTSE 100, NIKKEI 225, SP 500, and DAX 30 in the post-COVID-19 period (18.11.2019-23.11.2020).

\begin{tabular}{|c|c|c|c|c|c|c|}
\hline \multicolumn{3}{|c|}{ Shannon } & \multicolumn{2}{|c|}{ Tsallis } & \multirow{2}{*}{$\begin{array}{l}\text { Renyi } \\
\text { Value }\end{array}$} & \multirow{2}{*}{$\begin{array}{l}\text { Approximate entropy } \\
\text { Value }\end{array}$} \\
\hline Method & Value & $\mathrm{q}$ & Value & $\mathrm{r}$ & & \\
\hline \multicolumn{7}{|l|}{ ISE 30} \\
\hline ML & 5.557801 & 0 & 254.0000000 & 0 & 5.541264 & \multirow{4}{*}{0.605173} \\
\hline MM & 5.558188 & 0.2 & 103.9217249 & 0.25 & 5.540389 & \\
\hline Jefferys & 5.557804 & 0.4 & 44.6150090 & 0.5 & 5.539521 & \\
\hline Laplace & 5.557806 & 0.6 & 20.4188729 & 1 & 5.537801 & \\
\hline SG & 5.557801 & 0.8 & 10.1368950 & 2 & 5.534431 & \\
\hline Minimax & 5.557813 & 1 & 5.5378010 & 4 & 5.527964 & \\
\hline CS & 5.557801 & 1.2 & 3.3479548 & 8 & 5.516089 & \\
\hline \multirow[t]{2}{*}{ Shrink } & 5.558543 & 1.4 & 2.2270007 & 16 & 5.496175 & \\
\hline & & 1.6 & 1.6064999 & 32 & 5.468754 & \\
\hline
\end{tabular}


TABLE 4: Continued.

\begin{tabular}{|c|c|c|c|c|c|c|}
\hline \multicolumn{3}{|c|}{ Shannon } & \multicolumn{2}{|c|}{ Tsallis } & \multirow{2}{*}{$\begin{array}{l}\text { Renyi } \\
\text { Value }\end{array}$} & \multirow{2}{*}{$\begin{array}{c}\text { Approximate entropy } \\
\text { Value }\end{array}$} \\
\hline Method & Value & $\mathrm{q}$ & Value & $\mathrm{r}$ & & \\
\hline & & 1.8 & 1.2350782 & 64 & 5.442340 & \\
\hline & & 2 & 0.9960515 & Infinite & 5.390417 & \\
\hline \multicolumn{7}{|l|}{ FTSE 100} \\
\hline ML & 5.539317 & 0 & 255.0000000 & 0 & 5.545177 & \\
\hline MM & 5.539395 & 0.2 & 104.2128898 & 0.25 & 5.543729 & 0.4216846 \\
\hline Jefferys & 5.539318 & 0.4 & 44.6980209 & 0.5 & 5.542269 & \\
\hline Laplace & 5.539319 & 0.6 & 20.4418658 & 1 & 5.539317 & \\
\hline SG & 5.539317 & 0.8 & 10.1430007 & 2 & 5.533302 & \\
\hline Minimax & 5.539326 & 1 & 5.5393168 & 4 & 5.520987 & \\
\hline CS & 5.539317 & 1.2 & 3.3482870 & 8 & 5.496723 & \\
\hline \multirow[t]{3}{*}{ Shrink } & 5.539468 & 1.4 & 2.2270537 & 16 & 5.458418 & \\
\hline & & 1.6 & 1.6064983 & 32 & 5.421958 & \\
\hline & & 1.8 & 1.2350713 & 64 & 5.398850 & \\
\hline \multicolumn{7}{|c|}{ NIKKEI 225} \\
\hline ML & 5.541764 & 0 & 255.000000 & 0 & 5.545177 & \\
\hline MM & 5.541786 & 0.2 & 104.251176 & 0.25 & 5.544299 & 0.4849035 \\
\hline Jefferys & 5.541764 & 0.4 & 44.723779 & 0.5 & 5.543437 & \\
\hline Laplace & 5.541764 & 0.6 & 20.454859 & 1 & 5.541764 & \\
\hline SG & 5.541764 & 0.8 & 10.148825 & 2 & 5.538606 & \\
\hline Minimax & 5.541767 & 1 & 5.541764 & 4 & 5.532970 & \\
\hline CS & 5.541764 & 1.2 & 3.349274 & 8 & 5.523834 & \\
\hline \multirow[t]{4}{*}{ Shrink } & 5.541811 & 1.4 & 2.227440 & 16 & 5.510553 & \\
\hline & & 1.6 & 1.606647 & 32 & 5.490232 & \\
\hline & & 1.8 & 1.235127 & 64 & 5.457949 & \\
\hline & & 2 & 0.996068 & Infinite & 5.394338 & \\
\hline \multicolumn{7}{|l|}{ SP 500} \\
\hline ML & & 0 & 255.0000000 & 0 & 5.545177 & \\
\hline MM & 5.541305 & 0.2 & 104.240513 & 0.25 & 5.544141 & 0.484537 \\
\hline Jefferys & 5.541149 & 0.4 & 44.7167917 & 0.5 & 5.543124 & \\
\hline Laplace & 5.54115 & 0.6 & 20.4514234 & 1 & 5.541148 & \\
\hline SG & 5.541148 & 0.8 & 10.1473229 & 2 & 5.537413 & \\
\hline Minimax & 5.541157 & 1 & 5.5411479 & 4 & 5.530728 & \\
\hline CS & 5.541148 & 1.2 & 3.3490311 & 8 & 5.519871 & \\
\hline \multirow[t]{4}{*}{ Shrink } & 5.541472 & 1.4 & 2.2273475 & 16 & 5.504498 & \\
\hline & & 1.6 & 1.6066119 & 32 & 5.485190 & \\
\hline & & 1.8 & 1.2351145 & 64 & 5.463312 & \\
\hline & & 2 & 0.9960633 & Infinite & 5.410064 & \\
\hline \multicolumn{7}{|l|}{ DAX 30} \\
\hline ML & 5.42371 & 0 & 226.0000000 & 0 & 5.424950 & \\
\hline MM & 5.540173 & 0.2 & 104.2217368 & 0.25 & 5.543865 & 0.5196777 \\
\hline Jefferys & 5.540133 & 0.4 & 44.7046841 & 0.5 & 5.542587 & \\
\hline Laplace & 5.540133 & 0.6 & 20.4455670 & 1 & 5.540132 & \\
\hline SG & 5.540132 & 0.8 & 10.1448044 & 2 & 5.535607 & \\
\hline Minimax & 5.540138 & 1 & 5.5401324 & 4 & 5.527909 & \\
\hline CS & 5.540132 & 1.2 & 3.3486380 & 8 & 5.516591 & \\
\hline \multirow[t]{4}{*}{ Shrink } & 5.540219 & 1.4 & 2.2271995 & 16 & 5.503120 & \\
\hline & & 1.6 & 1.6065573 & 32 & 5.489558 & \\
\hline & & 1.8 & 1.2350947 & 64 & 5.475649 & \\
\hline & & 2 & 0.9960562 & Infinite & 5.432999 & \\
\hline
\end{tabular}



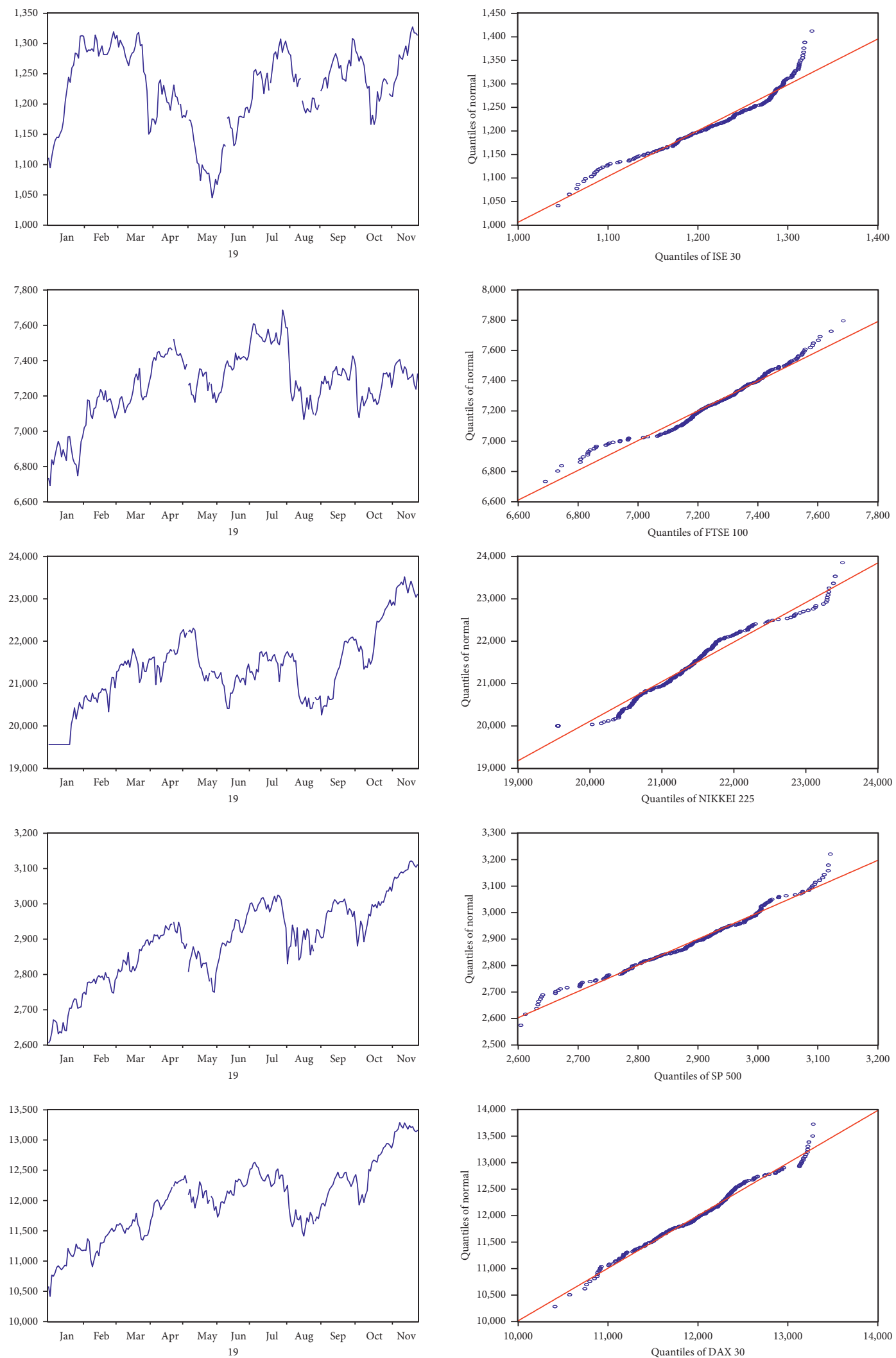

FIGURE 1: Data of world indices graphs and quantile graphs in the pre-COVID-19 period (02.01.2019-17.11.2019). 

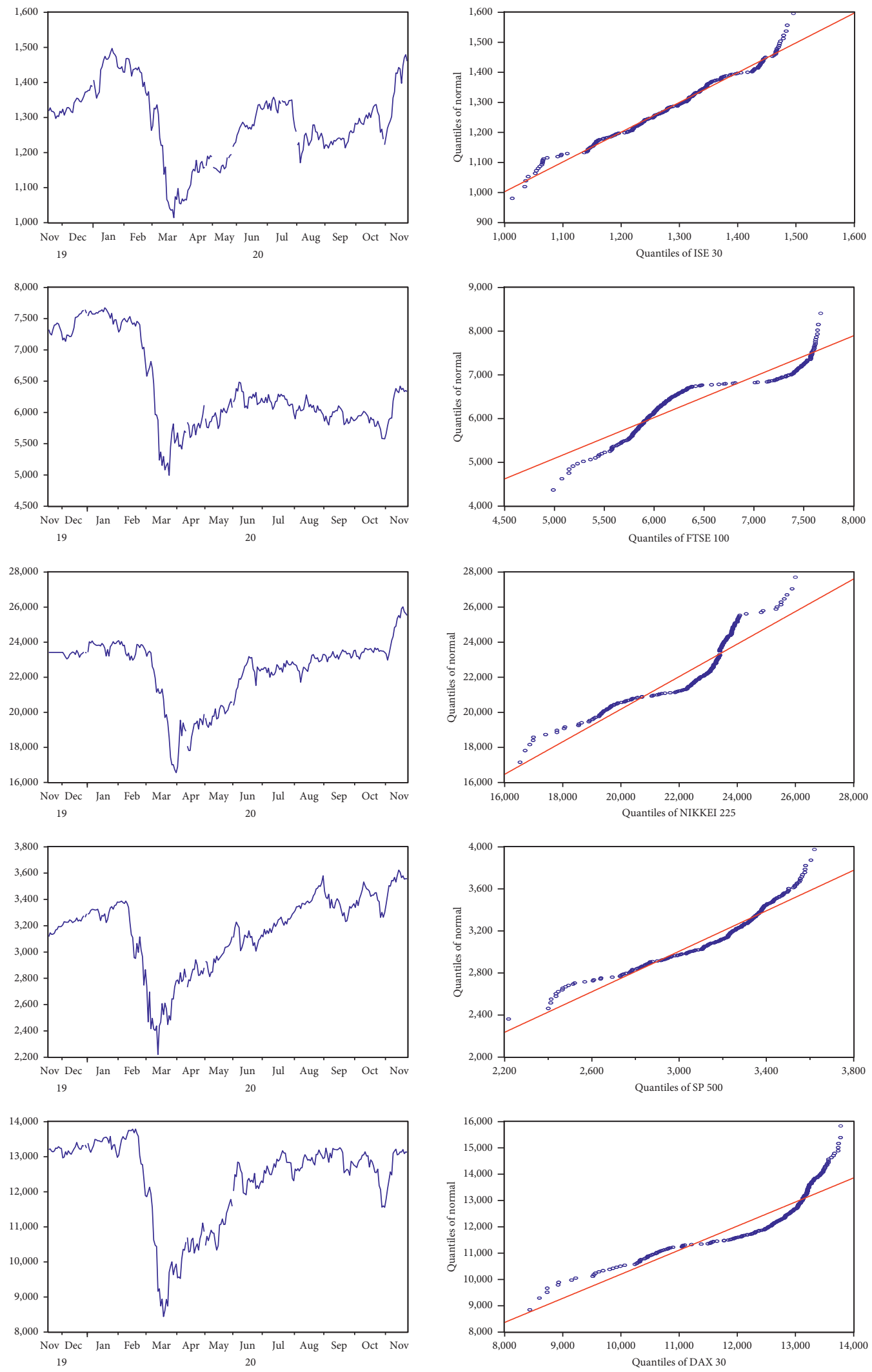

Figure 2: Data of world indices graphs and quantile graphs in the post-COVID-19 period (18.11.2019-23.11.2020). 


$$
\begin{aligned}
S_{1}(\rho) & =\lim _{q \longrightarrow 1} S_{q}(\rho), \\
\frac{d}{d q}\left(\frac{1}{1-q} \log \left(\sum_{i} \rho(i)^{q}\right)\right)_{q=1} & =-\sum_{i} \rho(i) \log \rho(i) .
\end{aligned}
$$

For $q=\infty$, acquire the min-entropy:

$$
S_{\infty}(\rho)=-\log \max _{i} \rho(i)=\log \min _{i} \frac{1}{\rho(i)} .
$$

2.2. Tsallis Entropy. For any positive real number $\alpha$, the entropy of order $\alpha$ of probability measure $p$ on finite set $X$ is defined as

$$
S_{\alpha}(p)= \begin{cases}\frac{1}{\alpha-1}\left(1-\sum_{i \in X} p_{i}^{\alpha}\right), & \text { if } \alpha \neq 1, \\ -\sum_{i \in X} p_{i} \ln p_{i}, & \text { if } \alpha=1 .\end{cases}
$$

The characterization of the Tsallis entropy is the same as that of the Shannon entropy except that for the Tsallis entropy, the degree of homogeneity under convex linearity condition is $\alpha$ instead of 1 .

\section{Results}

3.1. Data Set. We utilize the world indices of ISE 30, FTSE 100, SP 500, NIKKEI 225, and DAX 30 in the pre-COVID-19 period (02.01.2019-17.11.2019) and post-COVID-19 period (18.11.2019-23.11.2020). Tables 1 and 2 summarize the statistics data of world indices of ISE 30, FTSE 100, SP 500, NIKKEI 225, and DAX 30 before and after the coronavirus pandemic. Tables 1 and 2 indicate varied average values for the data set, and the suitable standard deviations are varied. In Table 2, skewness for data set is negative; in Table 1, except for NIKKEI 225, others are negative. The kurtosis of two data sets is higher than $l$. The Jarque-Bera (JB) test indicates that the normality of distribution for every series is strongly refused at 0.05 level, which means the overall energy terms' index distributions are nonnormal.

3.2. Conclusion: Entropy Approach. We apply the entropy technique for the volatility of world indices such as ISE 30, FTSE 100, SP 500, NIKKEI 225, and DAX 30 before and after the COVID-19 pandemic. For this, we compute Shannon, Tsallis, Renyi, and approximate entropies. In Tables 3 and 4, we initially provide varied forecasters for the Shannon entropy measure in the pre-COVID-19 period (02.01.2019-17.11.2019) and post-COVID-19 period (18.11.2019-23.11.2020). Later, we provide the Tsallis entropy for various values of the parameter and Renyi entropy measures for varied values of the parameter. Finally, we have obtained approximate entropy. When overall potential incidents have a similar probability, the entropy provides maximum value. In our experimental outcomes, volatility indicates variation; this model shows linear and nonlinear dynamics. We obtain from the numerical outcomes that overall entropies are positive, so features of our data series are nonlinear. We find that the world indices of ISE 30, FTSE 100, SP 500, NIKKEI 225, and DAX 30 series have a great value of approximate entropy before and after the coronavirus pandemic. In the data series, when looking at world indices volatility before the coronavirus pandemic in Table 3 and Figure 1, volatility is mostly seen in FTSE 100, followed by ISE 30, NIKKEI 225, SP 500, and DAX 30. Similarly, in Table 4 and Figure 2, when we look at world indices after the coronavirus pandemic, volatility is mostly seen in ISE 30, followed by DAX 30, NIKKEI 225, SP 500, and FTSE 100. It is concluded that before the coronavirus pandemic, FTSE 100 data series is of higher volatility than other data series. Similarly, after the coronavirus pandemic, ISE 30 data series is of higher volatility than other data series. For the Shannon entropy estimators, before the coronavirus pandemic, it is clear that FTSE 100 series have larger values. In a similar way, for the measures of Tsallis and Rényi entropies, if we take attention that $q$ and $r$ are close to 1, then we obtain the Shannon entropy. After the coronavirus pandemic, it is clear that ISE 30 series have larger values.

\section{Data Availability}

Data are available from the website www.bloomberght.com.

\section{Conflicts of Interest}

The authors declare that they have no conflicts of interest.

\section{Acknowledgments}

The authors thank http://www.bloomberght.com for the data set.

\section{References}

[1] K. J. Laidler, Thermodynamics In The World of Physical Chemistry, pp. 156-240, Oxford University Press, New York, NY, USA, 1995.

[2] C. Tsallis, "Possible generalization of Boltzmann-Gibbs statistics," Journal of Statistical Physics, vol. 52, no. 1-2, pp. 479-487, 1988.

[3] M. Rao, Y. Chen, B. C. Vemuri, and F. Wang, "Cumulative residual entropy: a new measure of information," IEEE Transactions on Information Theory, vol. 50, no. 6, pp. 1220-1228, 2004.

[4] S. Pincus, "Approximate entropy as an irregularity measure for financial data," Econometric Reviews, vol. 27, no. 4-6, pp. 329-362, 2008.

[5] M. R. Ubriaco, "Entropies based on fractional calculus," Physics Letters A, vol. 373, no. 30, pp. 2516-2519, 2009.

[6] L. S. Rompolis, "Retrieving risk neutral densities from European option prices based on the principle of maximum entropy," Journal of Empirical Finance, vol. 17, no. 5, pp. 918-937, 2010.

[7] M. M. Sati and N. Gupta, "Some characterization results on dynamic cumulative residual Tsallis entropy," Journal of Probability And Statistics, vol. 2015, Article ID 694203, 8 pages, 2015. 
[8] M. Sheraz, S. Dedu, and V. Preda, "Entropy measures for assessing volatile markets," Procedia Economics and Finance, vol. 22, pp. 655-662, 2015.

[9] D. Stosic, D. Stosic, T. Ludermir, W. de Oliveira, and T. Stosic, "Foreign exchange rate entropy evolution during financial crises," Physica A: Statistical Mechanics And Its Applications, vol. 449, pp. 233-239, 2016.

[10] L. Ponta and A. Carbone, "Information measure for financial time series: quantifying short-term market heterogeneity," Physica A: Statistical Mechanics And Its Applications, vol. 510, pp. 132-144, 2018.

[11] A. H. Khammar and S. M. A. Jahanshahi, "On weighted cumulative residual Tsallis entropy and its dynamic version," Physica A: Statistical Mechanics And Its Applications, vol. 491, pp. 678-692, 2018.

[12] A. M. Karakaş, "Entropy approach for volatility of ethereum and bitcoin," Asian Journal of Business and Management, vol. 7, no. 1, 2019.

[13] K. A. Metin, "Volatility measurement of the world indices using different entropy methods," Thermal Science, vol. 23, no. Suppl. 6, pp. 1849-1861, 2019.

[14] M. İnç, Z. S. Korpinar, M. M. Al Qurashi, and D. Baleanu, “A new method for approximate solutions of some nonlinear equations: residual power series method," Advances in Mechanical Engineering, vol. 8, no. 4, Article ID 1687814016644580, 2016.

[15] B. Acay and M. Inc, "Fractional modeling of temperature dynamics of a building with singular kernels," Chaos Solitons \& Fractals, vol. 142, Article ID 110482, 2020.

[16] A. Houwe, M. Inc, S. Y. Doka, B. Acay, and L. V. C. Hoan, "The discrete tanh method for solving the nonlinear differential-difference equations," International Journal of Modern Physics B, vol. 34, no. 19, Article ID 2050177, 2020.

[17] M. A. Akinlar, M. Inc, J. F. Gómez-Aguilar, and B. Boutarfa, "Solutions of a disease model with fractional white noise," Chaos Solitons \& Fractals, vol. 137, Article ID 109840, 2020.

[18] M. A. Akinlar, F. Tchier, and M. Inc, "Chaos control and solutions of fractional-order Malkus waterwheel model," Chaos, Solitons \& Fractals, vol. 135, Article ID 109746, 2020.

[19] Z. Korpinar, F. Tchier, M. Inc, F. T. Bousbahi, F. M. Tawfiq, and M. A. Akinlar, "Applicability of time conformable derivative to Wick-fractional-stochastic PDEs," Alexandria Engineering Journal, vol. 59, no. 3, pp. 1485-1493, 2020.

[20] M. S. Hashemi, M. Inc, and A. Yusuf, "On three-dimensional variable order time fractional chaotic system with nonsingular kernel," Chaos, Solitons \& Fractals, vol. 133, Article ID 109628, 2020.

[21] S. Qureshi, A. Yusuf, A. Ali Shaikh, M. Inc, and D. Baleanu, "Mathematical modeling for adsorption process of dye removal nonlinear equation using power law and exponentially decaying kernels," Chaos: An Interdisciplinary Journal of Nonlinear Science, vol. 30, no. 4, Article ID 043106, 2020. 